Recebido em 12/2019. Aceito para publicação em 08/2020.

\title{
EFEITOS NEUROPROTETORES DA HIDROCORTISONA EM LINHAGEM DE NEUROBLASTOMA DE MURINO (NEURO-2A) SOB ESTRESSE OXIDATIVO
}

\author{
NEUROPROTECTOR EFFECTS OF HYDROCORTISONE IN MURIN \\ NEUROBLASTOMA LINE (NEURO-2A) UNDER OXIDATIVE STRESS
}

\author{
Rafaella Carvalho Rossato ${ }^{1}$ \\ Jéssica Cristina Pinto ${ }^{2}$ \\ Carlos Dailton Guedes de Oliveira Moraes ${ }^{3}$ \\ Jessica Tereza Guedes de Oliveira Moraes ${ }^{4}$ \\ Geisa Nogueira Salles 5 \\ Cristina Pacheco Soares ${ }^{6}$
}

Resumo: A Doença de Alzheimer é um tipo de demência que acomete milhões de pessoas, sendo responsável por $60 \%$ de todos os casos de doenças neurodegenerativas. Embora não tenha cura, diversas estratégias de estudo vêm sendo desenvolvidas a fim de elucidar os mecanismos da doença. Estudos recentes abordam os benefícios do cortisol em aspectos imunológicos, musculares, renais, respostas inflamatórias e até mesmo em patologias neurodegenerativas. A hidrocortisona é um medicamento sintético utilizado para simular o cortisol. Deste modo, o estudo explora os efeitos da hidrocortisona na senescência neural, objetivando analisar seu efeito neuroprotetor. Assim, desenvolveu-se um modelo experimental in vitro de estresse oxidativo, induzido por peróxido de hidrogênio na linhagem celular Neuro-2a (Neuroblastoma de Murino) a fim de simular aspectos característicos da Doença de Alzheimer. Foram então realizados experimentos de viabilidade e morfologia celular. A hidrocortisona em baixa concentração promoveu aumento na viabilidade celular, enquanto que o peróxido de hidrogênio diminuiu a viabilidade celular, ocorrendo o efeito de estresse oxidativo. No aspecto morfológico, a hidrocortisona preservou os prolongamentos das células, já o peróxido de hidrogênio fez com que os prolongamentos retraíssem, assim perdendo as sinapses. Com os resultados obtidos, pode-se concluir que a hidrocortisona preservou a célula neural do efeito do estresse oxidativo.

Palavras-chave: Doença de Alzheimer; estresse oxidativo; hidrocortisona; neuroproteção.

Abstract: Alzheimer's disease (AD) is a type of dementia that affects millions of people, accounting for $60 \%$ of all cases of neurodegenerative diseases. Although there is no cure, several study strategies have been developed to elucidate the mechanisms of the disease. Recent studies approach benefits of cortisol in immunological, muscular, renal aspects, inflammatory responses and even neurodegenerative pathologies. Hydrocortisone is a synthetic medicine used to simulate cortisol. Therefore, this study explores the effects of hydrocortisone on neural senescence, aiming to analyze its neuroprotective effect. Thus, an in vitro experimental model of oxidative stress was developed, induced by hydrogen peroxide in the Neuro-2a cell line (Murine Neuroblastoma) for the purpose of mimetizing aspects characteristic of Alzheimer's Disease. Cell viability and morphology experiments were conducted. Low concentration of hydrocortisone promoted an increase in cell viability, whereas hydrogen peroxide decreased cell viability, with the effect of oxidative stress. In the morphological aspect, hydrocortisone preserved cell projections, while hydrogen peroxide caused the projections to retract, thus losing synapsis. With the results obtained, it can be concluded that hydrocortisone preserved the neural cell from the effect of oxidative stress.

Keywords: Alzheimer's disease; oxidative stress; hydrocortisone; neuroprotection.

\footnotetext{
1 Universidade do Vale do Paraíba - Univap, Brasil. E-mail: rafaella.rossato@hotmail.com.

2 Universidade do Vale do Paraíba - Univap, Brasil. E-mail: jessy.crys@hotmail.com.

3 Universidade do Vale do Paraíba - Univap, Brasil. E-mail: carlosdailtongom@gmail.com.

4 Universidade do Vale do Paraíba - Univap, Brasil. E-mail: j.t.guedess@gmail.com.

5 Universidade do Vale do Paraíba - Univap, Brasil. E-mail: geisa_salles@yahoo.com.br.

6 Universidade do Vale do Paraíba - Univap, Brasil. E-mail: cpsoares@univap.br.
} 


\section{INTRODUÇÃO}

A Doença de Alzheimer (DA) tem esse nome devido ao relato do médico neurologista alemão Dr. Alois Alzheimer, que em 1906 fez observações como a alteração anatômica e histologia no tecido cerebral de uma mulher com um conjunto de confusões mentais e comportamentais. Deste modo, iniciando o estudo e caracterizando o que se conhece hoje como as definições clínicas da DA (EVANGELISTI et al., 2014; CAYTON, 2016).

A DA corresponde a $60 \%$ dos quadros demenciais, sendo prevalente em todo o mundo. Atualmente, cerca de 35,5 milhões de pessoas convivem com essa doença, sendo estimado que esse número dobre a cada 20 anos em países de baixo e médio rendimento. Deste modo, a DA caracteriza-se como uma doença de grande impacto socioeconômico, podendo ser acompanhada junto com o crescimento da população idosa, pois o aumento da expectativa deve acarretar aumento da população com esta patologia. Atualmente, a DA é tratada com fármacos que atuam como inibidores de acetilcolinesterase, entre os mais utilizados estão rivastigmina, donepezila e galantamina. Contudo, estes tratamentos são limitados, apenas controlando os sintomas, favorecendo a sobrevida do paciente e melhorando sua qualidade de vida. $O$ prognostico piora quando é realizado um diagnóstico tardio, minimizando os efeitos do tratamento, bem como a qualidade de vida do paciente (PRINCE; JACKSON, 2010; FALCO et al., 2016).

Estudo cronológico observou que a progressão da doença leva a perda dos prolongamentos neurais, comprometimento de seu entorno e redução de neurônios ativos, deste modo acarretando atrofia cerebral, alterando a conectividade das sinapses, reduzindo o metabolismo celular, bem como perda da capacidade da recuperação neural. Uma das funções afetadas na DA é o cognitivo, responsável pelas atividades do cotidiano, como perda da capacidade de planejar, dificuldade na produção da fala e escrita, levando a incapacidade do indivíduo afetado a desempenhar as atividades para cuidar de si mesmo, este sintomas podem se agravar caso o paciente não tenha estímulos cognitivo, social, físico e ambiental (FELIPPE, 2013; FALCO et al., 2016).

Sabe-se que a DA apresenta relação com mutações da proteína TAU, que acarreta acúmulo de proteína beta amiloide, formação de placa senil, recrutamento de células brancas como micróglia e astrócitos, disfunção no metabolismo da glicose. Além disso, outro motivo que favorece o aparecimento da DA é o estresse oxidativo, que acarreta um desequilíbrio de espécies reativas de oxigênio (EROs), normalmente produzidas pelo metabolismo corporal, porém quando produzidas em excesso, impedem a célula de defender-se e neutralizar EROs, dificultando o reparo celular, proporcionando danos nas biomoléculas (DNA, lipídios, proteínas). Quando estes danos não são reparados, acabam comprometendo o funcionamento da célula neural, levando a um quadro de inflamação local, causando a morte celular (BARBOSA; MEDEIROS; AUGUSTO, 2006; CRUZAT et al., 2007; RABELO, 2012). 
Estudos vêm sendo realizados com o objetivo de realizar um diagnóstico precoce da doença e tratamentos mais eficazes em busca da cura da DA. A hidrocortisona, modelo sintético do cortisol, de acordo com HAM, 2017 promove um efeito neuroprotetor na doença de Parkinson. A literatura pouco abrange o benefício do cortisol em doenças neurodegenerativas, por outro lado, há estudos apontando que o cortisol é encontrado em altas concentrações em indivíduos com DA, deve-se a presença do estresse metabólico, por consequência inibindo mecanismos de reparo neural. Contudo, o cortisol também tem efeitos positivos no organismo dependendo da sua concentração. Em situações de estresse, o cortisol em baixas concentrações, promove a manutenção da produção de glicose, ações anti-inflamatórias, regulação imunológica, muscular e renal (DAMIANI et al., 2015; SOARES; ALVES, 2006; BUENO; GOUVÊA, 2011).

Portanto, o presente estudo avaliou os efeitos da hidrocortisona em condições de estresse com peróxido de hidrogênio $\left(\mathrm{H}_{2} \mathrm{O}_{2}\right)$ na linhagem celular Neuro-2a (Neuroblastoma de Murino), simulando o estresse oxidativo característico da DA. Assim, o objetivo foi analisar como as células neurais se comportam em modelo in vitro prétratadas com hidrocortisona e posteriormente estressadas $\mathrm{H}_{2} \mathrm{O}_{2}$, verificando sua eficácia, contribuindo com a literatura e colaborando com um futuro e possível tratamento para a DA.

\section{MATERIAIS E MÉTODOS}

\subsection{Linhagem Celular}

A linhagem celular Neuro-2a (Neuroblastoma de Murino ATCC - CCL-131), foi adquirida do Instituto Adolfo Lutz, São Paulo/SP, e cultivada no Laboratório de Dinâmica de Compartimentos Celulares, do IP\&D, da UNIVAP. As células foram mantidas em garrafas de cultura de $25 \mathrm{~cm}^{2}$, meio DMEM/F12 (Gibco Dulbecco's Modified Eagle Medium: Nutrient Mixture) suplementado com 10\% de Soro Fetal Bovino (SFB) e 1\% de antibiótico e antimicótico (AA) e incubadas em estufa a $37^{\circ} \mathrm{C}$ com atmosfera de $5 \%$ de $\mathrm{CO}_{2}$.

\subsection{Plaqueamento}

Ao atingir confluência entre $3 \times 10^{6}$ e $4 \times 10^{6}$ células/garrafa, as células foram retiradas da garrafa com auxílio da solução de tripsina $0,1 \%$ e contadas com o auxílio de citômetro de imagem, TALI ${ }^{\mathrm{TM}}$ Image-Based Cytometer Invitrogen ${ }^{\mathrm{TM}}$ (ThermoFischer Scientific- Waltham, Massachusetts, EUA) (ROSSATO et al., 2019). A seguir foram plaqueadas $1 \times 10^{4}$ células $/ \mathrm{mL}$ para os testes de viabilidade celular em placas de 96 poços. Para análise de morfologia celular foram utilizadas $1 \times 10^{5}$ células $/ \mathrm{mL}$, cultivadas em placas de 24 poços, contendo lamínulas. As células foram cultivadas em meio de cultura DMEM/F12 suplementado com $10 \%$ de soro fetal bovino (SFB) para adesão das 
células em estufa a uma temperatura de $37^{\circ} \mathrm{C}$ e $5 \%$ de $\mathrm{CO}_{2}$, overnight (MORAES et al. 2019).

\subsection{Grupos Experimentais}

a) Grupo Controle: células cultivadas em meio de cultura e não expostas ao agente estressor, nem à hidrocortisona.

b) Grupo Hidrocortisona: células cultivadas em meio de cultura e expostas à hidrocortisona na concentração de $100 \mu \mathrm{M}$ por $24 \mathrm{~h}$.

c) Grupo $\mathrm{H}_{2} \mathrm{O}_{2}$ : células cultivadas em meio de cultura e expostas apenas ao agente estressor $\mathrm{H}_{2} \mathrm{O}_{2}$ na concentração de $2,5 \mathrm{mM}$ por $24 \mathrm{~h}$.

d) Grupo Pré-tratamento com Hidrocortisona: células cultivadas em meio de cultura e expostas à hidrocortisona por $24 \mathrm{~h}$ e posteriormente ao $\mathrm{H}_{2} \mathrm{O}_{2}$ por $24 \mathrm{~h}$.

e) Grupo morte: Células expostas a alta concentração de $\mathrm{H}_{2} \mathrm{O}_{2}$

\subsection{Teste de Viabilidade Celular}

Após o tratamento, o meio de cultura foi retirado, e as células incubadas com 100 $\mu \mathrm{L}$ da solução de Cristal Violeta por 4 minutos em temperatura ambiente. Em seguida lavadas em água corrente para remover o excesso de corante. Depois disso, as células foram incubadas com $200 \mu \mathrm{L}$ de dimetilsulfóxido (DMSO) por $1 \mathrm{~h}$. Após a incubação foi realizada a leitura em espectrofotômetro a $570 \mathrm{~nm}$ (SpectraCount - Packard) (MORAES, et al. 2019; ROSSATO et al., 2019).

\subsection{Análise da Morfologia Celular}

A fim de avaliar as alterações morfológicas, foi realizada a Microscopia Eletrônica de Varredura (MEV), deste modo, analisando as modificações na membrana e projeções das células em cada grupo estudado (SALLES et al., 2017; SALLES et al., 2018).

\subsubsection{Fixação}

Utilizou-se solução fixadora, contendo tampão cacodilato $0,1 \mathrm{M}(2,5 \mathrm{~mL})$, Glutaraldeído 2,5\% (0,50 mL) e paraformaldeído 4\% (2,0 mL). Esta solução foi incubada por $1 \mathrm{~h}$. Após este período, foi retirada a solução fixadora e lavadas 2 vezes com solução tampão cacodilato (SALLES et al., 2017; SALLES et al., 2018).

\subsubsection{Desidratação}

A desidratação foi realizada com acetona, em concentrações crescentes sendo 
elas: acetona nas concentrações de 30\%, 50\%, 70\%, 90\% e 100\%, por 10 minutos cada. Em seguida incubadas com acetona 100\% + HMDS (Hexametildisilazano) na proporção (1:1) por 10 minutos e por fim com HMDS puro por 10 minutos. Retirou-se o HMDS após esse tempo e deixou-se secar em estufa por 24 h (SALLES et al., 2017; SALLES et al., 2018).

\subsubsection{Metalização}

Em relação à metalização: após a secagem, as lamínulas foram retiradas das placas e colocadas sob stub e metalizadas no equipamento EMITECH K 550 X® que tem a função de pulverizar metais não oxidantes como ouro e platina sobre as amostras (SALLES et al., 2017; SALLES et al., 2018).

\subsubsection{Análise}

A análise foi realizada ao Microscópio Eletrônico de Varredura EVO MA10-Zeiss $®$ sendo capturadas as imagens dos grupos, para avaliação das alterações de morfologia celular (SALLES et al., 2017; SALLES et al., 2018).

\subsection{Análise Estatística}

Os dados foram realizados com $n=8$, e repetidos 3 vezes de forma independente para obter confirmação, apresentados na forma de média \pm desvio padrão, comparados pelo teste de ANOVA ONE-WAY, sendo confirmado pelo teste Tukey. A significância estatística foi admitida com $p<0,05$. Para a realização das análises estatísticas e gráficos foi utilizado o software GraphPad Prisma 6®.

\section{RESULTADOS}

\subsection{Teste de Viabilidade Celular}

Para o teste de viabilidade celular foi utilizado o ensaio de cristal violeta, que tem por objetivo verificar a densidade celular pela coloração do DNA, para avaliação de citotoxicidade. Os resultados obtidos demonstram que as concentrações de $\mathrm{H}_{2} \mathrm{O}_{2}$ a partir de $100 \mu \mathrm{M}$ alteram a proliferação celular quando comparadas ao grupo controle, aumentando significativamente até a concentração de $5 \mathrm{mM}$, conforme a figura 1. Com o objetivo de estressar as células sem causar morte celular, a concentração de 2,5 mM de $\mathrm{H}_{2} \mathrm{O}_{2}$ foi utilizada para o processo de estresse celular. Para controle positivo de morte celular, foi utilizado $\mathrm{H}_{2} \mathrm{O}_{2} 200$ volumes.

Para avaliação de hidrocortisona sobre as células Neuro-2a, foi realizado teste de 
cristal violeta para avaliação da dosagem ideal para utilização na cultura sem danos celulares. Os resultados obtidos demonstram que a dosagem ideal é de $100 \mu \mathrm{M}$, uma vez que apresentou um aumento na viabilidade celular.

Figura 1 - Viabilidade Celular da linhagem Neuro-2a exposta a diferentes concentrações de $\mathrm{H}_{2} \mathrm{O}_{2}$. Os dados estão dispostos em ordem crescente da concentração de $\mathrm{H}_{2} \mathrm{O}_{2}$, no intervalo de $24 \mathrm{~h}$. O primeiro é o grupo controle, em seguida as demais concentrações distribuídas de 0,1 $\mu \mathrm{M}$ até $50 \mu \mathrm{M}$, não apresentando diferença estatística em relação ao controle. Outras concentrações como a de $100 \mu \mathrm{M}$ até $5 \mathrm{mM}$ apresentam diferença estatística em relação ao controle com $\mathrm{p}<0,0001$.

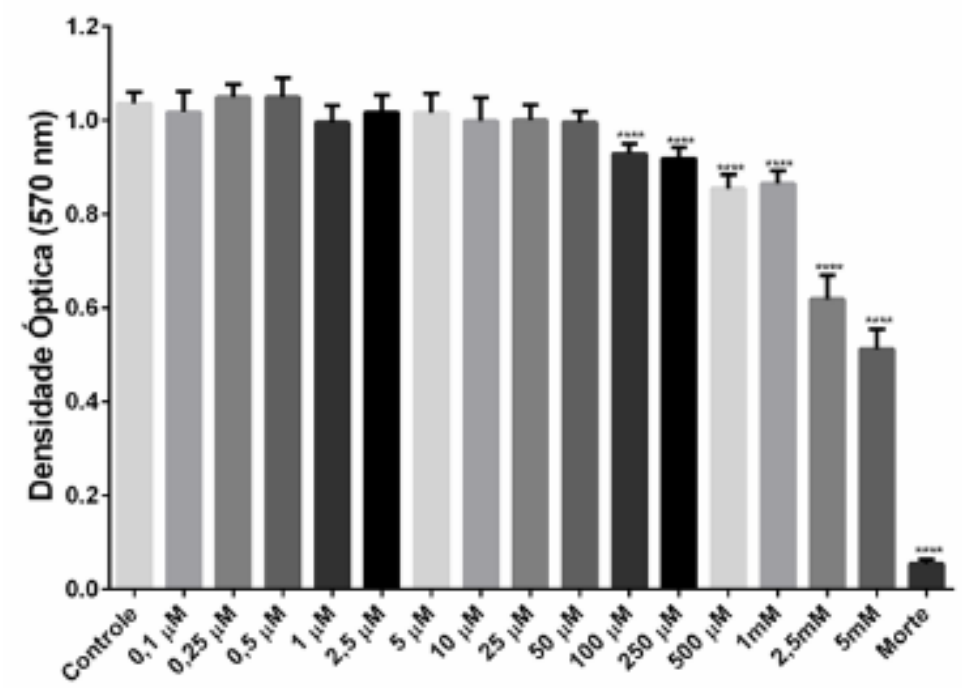

Fonte: Os autores. 
Figura 2 - Ensaio de Cristal Violeta na linhagem Neuro-2a. Os dados estão dispostos em ordem crescente da concentração de hidrocortisona, no intervalo de $24 \mathrm{~h}$, sendo que o primeiro é o grupo controle, em seguida as demais concentrações distribuídas de $50 \mu \mathrm{M}$ a $200 \mu \mathrm{M}$. O grupo de $150 \mu \mathrm{M}$ apresentou diferença estatística em relação ao grupo controle com $p<0,05$ e os grupos $100 \mu \mathrm{M}, 200 \mu \mathrm{M}$ e morte apresentaram diferença estatística comparada ao grupo controle com $p<0,0001$.

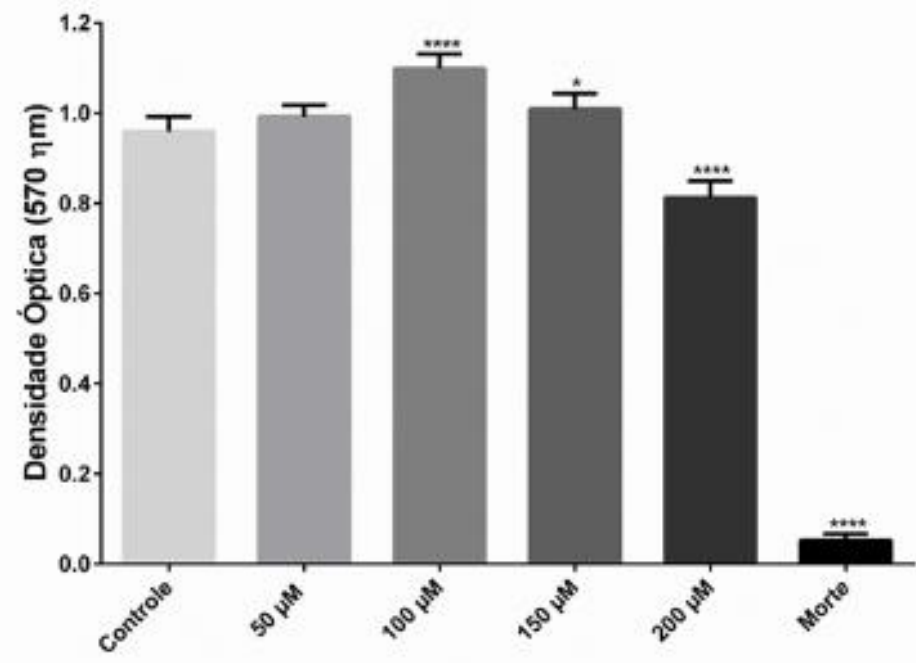

Fonte: Os autores.

Figura 3 - Ensaio de Viabilidade Celular na linhagem celular Neuro-2a, verificando o efeito neuroprotetor sob estresse oxidativo no intervalo de $24 \mathrm{~h}$. O grupo hidrocortisona $100 \mu \mathrm{M}$ não apresenta diferença estatística perante o grupo controle. Os grupos $\mathrm{H}_{2} \mathrm{O}_{2}$, pré-tratamento e morte apresentaram diferença estatística comparada ao grupo controle, com $p<0,0001$. $O$ grupo pré-tratamento comparado ao grupo $\mathrm{H}_{2} \mathrm{O}_{2}$ apresentou diferença estatística com $p<0,0001$.

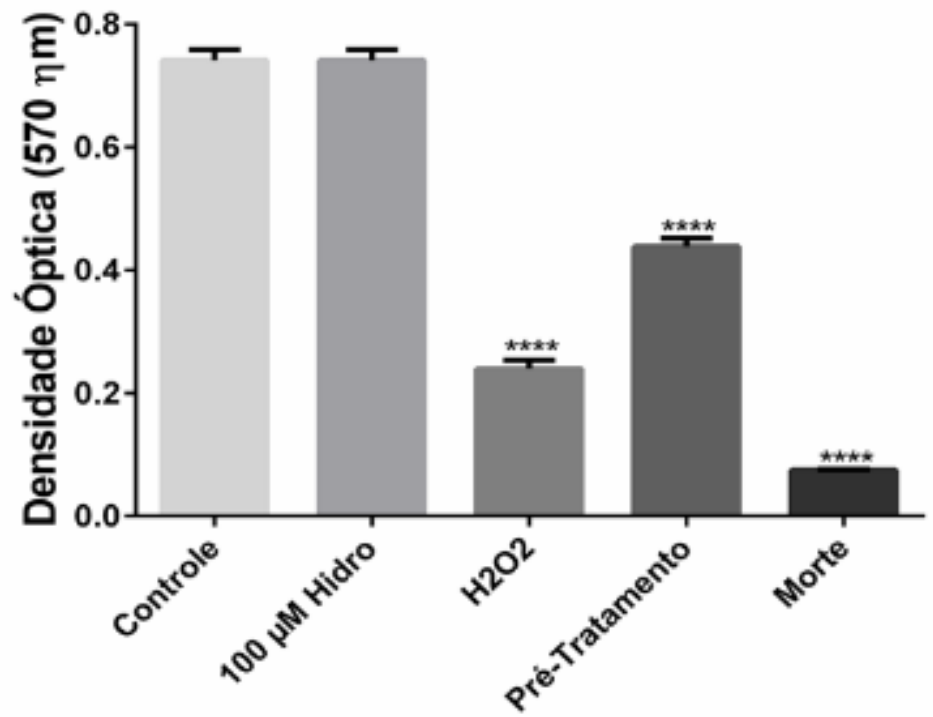

Fonte: Os autores.

\subsection{Microscopia Eletrônica de Varredura (MEV)}

O objetivo do uso da técnica é verificar a morfologia das células, analisando o efeito da hidrocortisona na linhagem celular Neuro-2a. Deste modo produzindo imagens de alta resolução da superfície da amostra. Além disso, pode ser verificado também que 
as imagens têm uma aparência tridimensional característica e são úteis para avaliar a estrutura superficial, bem como a diferenças entre cada grupo estudado (LIAW; ZHANG; KANNAN, 2019).

As imagens foram obtidas com aumento de 100 vezes, mostrando em maior campo a população celular e aumento de 1000 vezes, focando na morfologia da célula. Pode-se observar que o grupo hidrocortisona manteve-se preservada a população e também a morfologia celular em comparação ao grupo controle. Já o grupo $\mathrm{H}_{2} \mathrm{O}_{2}$ obteve diminuição na população celular e retração dos prolongamentos, assim perdendo a comunicação entre as células, sendo característica da DA. No grupo de pré-tratamento com hidrocortisona, percebe-se uma melhora nas características celulares em relação ao grupo $\mathrm{H}_{2} \mathrm{O}_{2}$, preservando os prolongamentos característicos de uma célula saudável. 
Figura 4 - Análise da Morfologia Celular. Micrografias obtidas por microscópio eletrônico de varredura (MEV) de células Neuro-2a. As imagens foram feitas com aumento de 100 vezes e com aumento de 1000 vezes nos grupos controle, hidrocortisona, $\mathrm{H}_{2} \mathrm{O}_{2}$, pré-tratamento com hidrocortisona.

\section{Controle}

\section{Hidrocortisona}
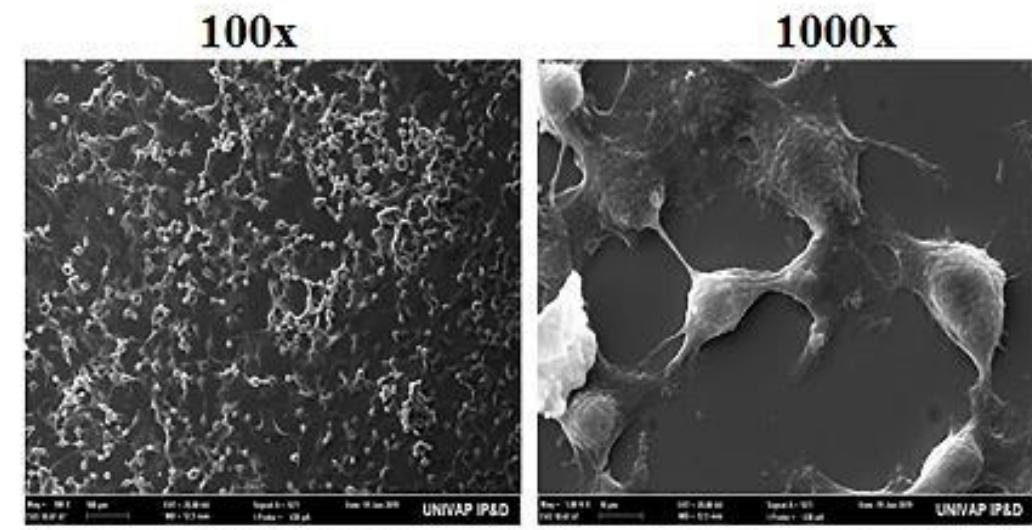

Estresse
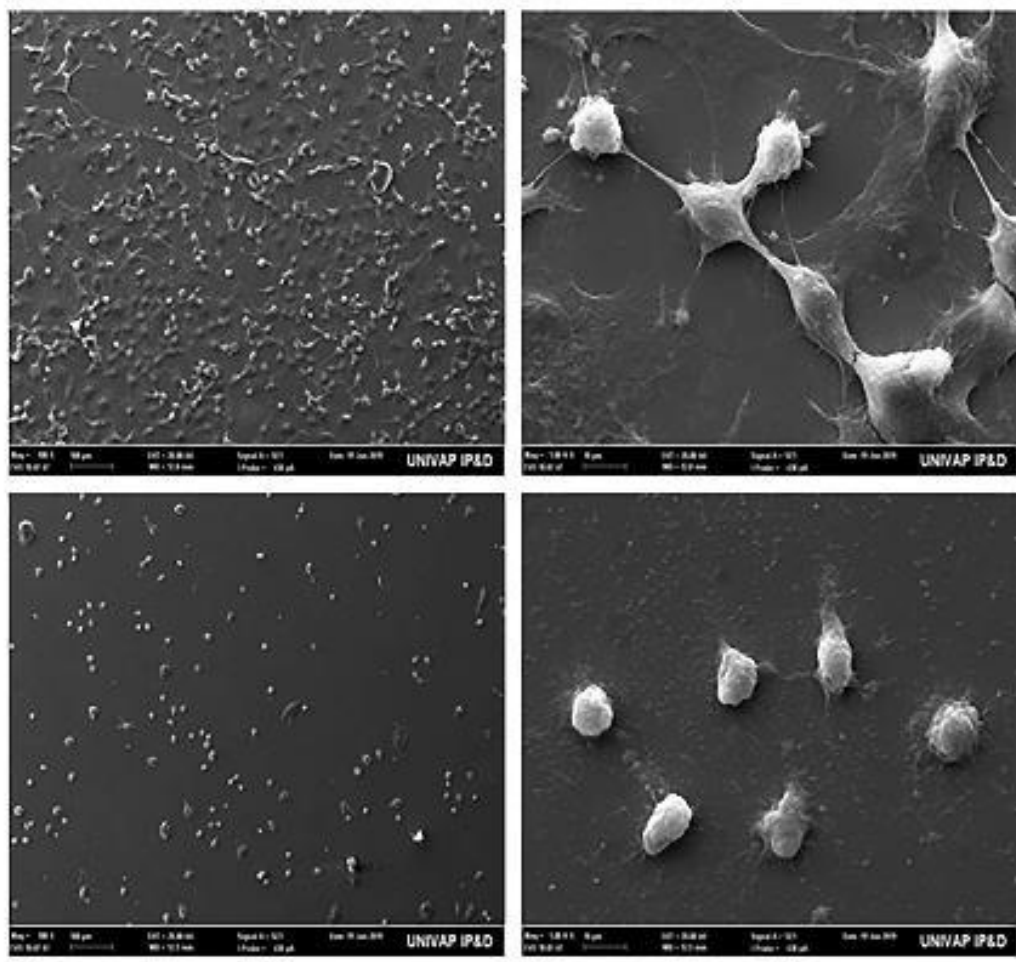

\section{Pré-Tratamento}
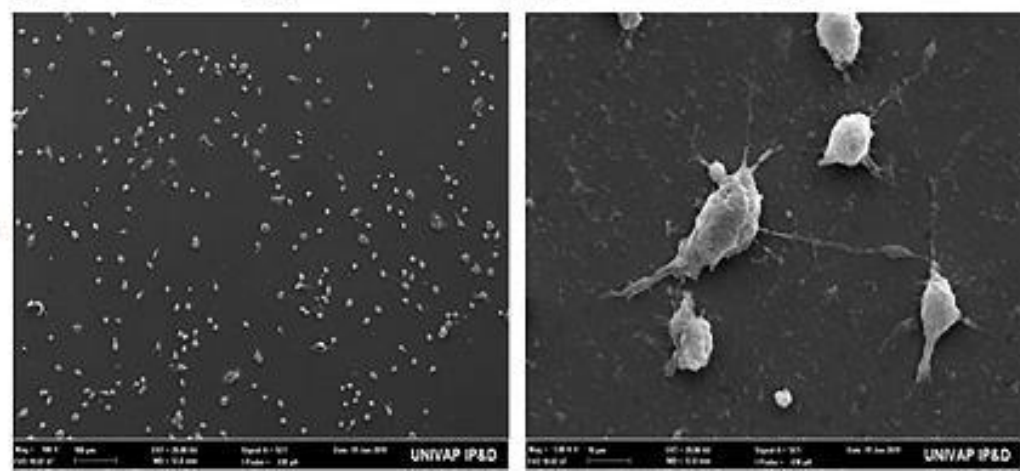

Fonte: Os autores. 


\section{DISCUSSÃO}

No estudo realizado com a linhagem celular Neuro-2a, foi possível verificar que foram responsivas ao tratamento. Os resultados dos ensaios de viabilidade celular $e$ microscopia eletrônica de varredura demonstraram a ação da hidrocortisona em diminuir o efeito do estresse oxidativo e a produção de EROs, característica da DA. Assim, esta doença neurodegenerativa que pode afetar áreas-chave do Sistema Nervoso Central, seja por falta de recepção/propagação de sinal no neurônio em si devido a sua mudança morfológica ou devido a sua morte ou devido a danos recorrentes ao estresse oxidativo será discutido mais adiante.

O modelo da DA realizado in vitro, no qual há liberação de EROs induzido pelo $\mathrm{H}_{2} \mathrm{O}_{2}$, foi realizado também nos estudos de Mayes et al., (2014) e Salles et al. (2017; 2018; 2020) e a partir destas análises foi possível determinar o dano que as EROs causam nas células neurais e verificar modos de impedir que tais danos ocorram de maneira total ou parcial.

Na Figura 1 podemos observar como as células da linhagem Neuro-2a reagem ao serem colocadas em concentrações crescentes de $\mathrm{H}_{2} \mathrm{O}_{2}$. A partir da concentração de $100 \mu \mathrm{L}$ as células começam a sofrer morte celular, porém para a pesquisa foi necessário que $\circ \mathrm{H}_{2} \mathrm{O}_{2}$ resultasse na morte de $\pm 50 \%$ da população celular $(2,5 \mathrm{mM})$, pois segundo SALLES et al $2018 \circ \mathrm{H}_{2} \mathrm{O}_{2}$ causa estresse oxidativo, resultando mudanças morfológicas, perda de interação e de função neural e posteriormente morte celular, conforme visto em estudo animal. Também demonstrado em nosso estudo in vitro com a curva de concentração com $\mathrm{H}_{2} \mathrm{O}_{2}$ na célula Neuro-2a (Figura 1), indicando uma citotoxicidade estatisticamente significativa em resposta ao estresse oxidativo estimulado pela incubação com $\mathrm{H}_{2} \mathrm{O}_{2}$. Os resultados obtidos corroboram (CRUZAT et al., 2007), que observaram falência neural em DA e HAM et al, 2017 que obteve resultados semelhantes em Doença de Parkinson (DP), com redução de $50 \%$ da viabilidade celular.

A Hidrocortisona, medicamento que mimetiza a Cortisol humano de acordo com alguns estudos, pode exercer o papel de indução ao estresse oxidativo em células hepáticas (ABOELWAFA; YOUSEF, 2015), proteção aos cardiomiócitos e auxílio na degradação da Ciclofosforina em níveis tóxicos (FLORIO et al., 2003), porém há também indícios de que a Hidrocortisona não induz e também não protege os rins do estresse oxidativo (EBRAHIMI et al., 2013), dentre outros, porém em células neuronais permanece uma lacuna sobre sua ação e a sua concentração de trabalho, isto foi abordado na Figura 2. Neste experimento com concentrações crescentes de hidrocortisona nas células neurais foi possível constatar que a concentração vista como a ideal para a Neuro-2a foi de $100 \mu \mathrm{L}$, este valor está parcialmente de acordo com estudos que visavam estabelecer a concentração de trabalho para a hidrocortisona, como os estudos realizado por Florio et al. (2003) estabeleceram concentrações crescentes para substâncias estudadas, porém não demonstraram os dados para estabelecer qual seria a ideal de Hidrocortisona para cada tipo de célula. Além disso, 
estudo de Ham et al. (2017), demonstrou que a concentração responsável por aumentar a viabilidade celular é de $100 \mu \mathrm{M}$, sendo que a linhagem SH-SY5Y (linhagem celular utilizada para estudo de doenças neurodegenerativas) obteve um resultado condizente com tal resultado da literatura, demonstrando o efeito positivo na viabilidade da célula neural de $50 \%$ a $70 \%$. Portanto, com base em nossos resultados e baseado neste estudo recente da literatura, estabeleceu-se a concentração de $100 \mu \mathrm{M}$ como agente neuroprotetor para os próximos experimentos.

Estas características de neuroproteção em relação à hidrocortisona pode ser verificado com os resultados de viabilidade celular obtidos na coloração de cristal violeta, conforme a figura 3 , sendo que a hidrocortisona (100 $\mu \mathrm{M})$ manteve a viabilidade celular, a concentração de $2,5 \mathrm{mM}$ do $\mathrm{H}_{2} \mathrm{O}_{2}$ diminuiu a viabilidade celular provocando o estresse, (característico da DA), e interessantemente, o grupo de pré-tratamento com hidrocortisona obteve uma melhora em sua viabilidade celular mesmo após o estresse induzido em sequência, estando de acordo com os estudos Florio et al. (2003), Ham et al. (2017) e Salles et al. (2020), sendo verificado a efeito de neuroproteção da hidrocortisona em resposta ao estresse oxidativo, demonstrado pela melhora da viabilidade celular.

Outras características que ocorre com as células neurais ao sofrerem estresse oxidativo é sua morfologia alterada, estando diretamente e indiretamente relacionada com as funções exercidas no sistema nervoso central. $\mathrm{Na}$ análise feita na Microscopia Eletrônica de Varredura, foi possível verificar qualitativamente a morfologia da célula Neuro-2a, estas imagens auxiliaram na confirmação dos dados estatísticos. Deste modo, as células presentes no grupo controle demonstram características de uma célula neural típica, bem como as imagens das células com o medicamento apresentaram normalidade na sua morfologia. Por outro lado, no grupo estresse é nítido observar a mudança morfológica das células neurais, perda dos prolongamentos e formato arredondado. Estas informações podem ser comparadas com Domínguez-Álvaro et al. (2019), no qual comparou células neuronais saudáveis e células com DA e foi possível constatar tais mudanças em sua morfologia. As imagens obtidas das células neurais submetidas ao pré-tratamento com hidrocortisona e depois ao estresse oxidativo simulando a DA, é possível observar que a morfologia das células neurais mantém os seus prolongamentos em algumas células se comparado ao grupo estresse, porém também é visto algumas células com formato mais arredondado constatando que a neuroproteção não abrangeu todas as células. Assim, confirmou-se morfologicamente o efeito da neuroproteção da hidrocortisona perante os resultados de viabilidade celular, por MEV, observando-se por micrografias características e o comportamento morfológico de cada célula. As imagens foram obtidas no aumento de 100 vezes, sendo possível visualizar a população celular, e no aumento de 1000 vezes para verificar a morfologia celular.

Na Figura 4 podemos verificar o comportamento das células Neuro-2a, expostas aos grupos já mencionados com aumento de 100 vezes e de 1000 vezes. O grupo 
hidrocortisona em comparação ao grupo controle com aumento de 100 vezes manteve a população celular em ambas as linhagens. O grupo estresse obteve uma redução no número de células, diminuindo assim a viabilidade das três linhagens e por fim o grupo de pré-tratamento com hidrocortisona, que em comparação ao grupo estresse apresentou um aumento populacional celular nas linhagens, deste modo confirmando os resultados obtidos no ensaio de cristal violeta, visto que foi verificado comportamento semelhante na quantidade da população celular. Para compreender melhor essas alterações estruturais, estudo de Morales, Farias e Maccioni (2010) verificou que o estresse oxidativo é causado por um grande número de EROs, sendo altamente prejudicial quando produzidos em excesso em nosso organismo, ocasionando alterações estruturais nas proteínas, lipídeos e ácidos nucleicos, levando à morte celular.

Com o aumento de 1000 vezes podemos observar a morfologia da célula. No grupo hidrocortisona em relação ao grupo controle, não houve modificação estrutural. Por outro lado, no grupo $\mathrm{H}_{2} \mathrm{O}_{2}$ houve modificação estrutural no citoesqueleto, retraindo os prolongamentos característicos de célula neural. Já no grupo pré-tratamento em comparação ao grupo $\mathrm{H}_{2} \mathrm{O}_{2}$, obteve uma melhora na morfologia celular, mantendo as projeções estelares ramificações das células. Esta característica pode estar relacionada ao depósito de proteína $\beta$-Amilóide, frutos da hiperfosforilação da proteína TAU de acordo com Cecchi et al. (2009), desenvolve uma alteração da fisiologia neural, principalmente nas sinapses, levando a um comprometimento celular e morte. Em concordância, Monteiro, Kandratavicius e Leite (2011) mostram que essa hiperfosforilação da proteína TAU resulta em sua deposição nos filamentos celulares, sendo responsável no processo de neurodegeneração que ocorre na DA. Deste modo, as imagens obtidas por MEV apresentam as alterações morfológicas das células prétratadas com hidrocortisona e estressadas oxidativamente simulando um fator característico da DA. Assim, concordando com os estudos realizados sobre a morfologia celular em condições de estresse, obtivemos resultados semelhantes. A hidrocortisona, visualmente, apresentou características neuroprotetoras capaz de manter a morfologia da linhagem Neuro-2a.

\section{CONCLUSÃO}

Pode-se concluir que a hidrocortisona possui efeito neuroprotetor na linhagem celular Neuro-2a analisada sob estresse oxidativo, simulando in vitro ambiente estressor característico da DA, assim abordando novos conceitos e novas possibilidades de tratamento, contribuindo também com a elucidação da patologia a partir da visão de diferentes aspectos.

\section{AGRADECIMENTOS}

Agradecemos à nossa orientadora Dra. Cristina Pacheco Soares, ao laboratório de Dinâmica e Compartimento Celular, onde ocorreu o desenvolvimento da pesquisa, e ao PIBIC-CNPq-UNIVAP pela bolsa auxilio nº 800985/2018-4. 


\section{REFERÊNCIAS}

ABOELWAFA, Hanaa R.; YOUSEF, Hany N. The ameliorative effect of thymol against hydrocortisone-induced hepatic oxidative stress injury in adult male rats. Biochemistry and cell biology, v. 93, n. 4, p. 282-289, 2015.

BARBOSA, Lívea Fujita; MEDEIROS, Marisa H. G.; AUGUSTO, Ohara. Danos oxidativos e neurodegeneração: o que aprendemos com animais transgênicos e nocautes?. Química Nova, v. 29, n. 6, p. 1352, 2006.

BUENO, Juliano Ribeiro; GOUVÊA, Cibele Marli Cação Paiva. Cortisol e exercício: efeitos, secreção e metabolismo. Revista Brasileira de Prescrição e Fisiologia do Exercício (RBPFEX), v. 5, n. 29, p. 1-7, 2011.

CAYTON, Harry. Tudo sobre doença de Alzheimer. São Paulo: Editora Andrei, 2016.

CECCHI, Cristina et al. A protective role for lipid raft cholesterol against amyloidinduced membrane damage in human neuroblastoma cells. Biochimica et Biophysica Acta (BBA)-Biomembranes, v. 1788, n.10, p. 2204-2216, 2009.

CRUZAT, Vinicius Fernandes et al. Aspectos atuais sobre estresse oxidativo, exercícios físicos e suplementação. Rev Bras Med Esporte, v. 13, n. 5, p. 336-342, 2007.

DAMIANI, Durval et al. Corticoterapia e suas repercussões: a relação custo-benefício. Pediatria (São Paulo), v. 23, p. 71-82, 2001.

DOMÍNGUEZ-ÁLVARO, M. et al. 3D Electron Microscopy study of synaptic organization of the normal human transentorhinal cortex and its possible alterations in Alzheimer's disease. eNeuro, v. 6, n. 4, 2019.

EBRAHIMI, Ali et al. How effective are alprostadil and hydrocortisone on reperfusion injury in kidney after distant organ ischemia? Journal of research in medical sciences: the official journal of Isfahan University of Medical Sciences, v. 18, n. 9 p. 755-758, 2013.

EVANGELISTI, Elisa et al. Plasma membrane injury depends on bilayer lipid composition in Alzheimer's disease. Journal of Alzheimer's Disease, v. 41, n. 1, p. 289-300, 2014.

FALCO, Anna et al. Alzheimer's disease: etiological hypotheses and treatment perspectives. Quimica Nova, v. 39, n. 1, p. 63-80, 2016.

FELIPPE, Lilian Assunção. Funções executivas, atividades de vida diária e habilidade motora de idosos com doenças neurodegenerativas. Campo Grande. 71f. Dissertação (Mestrado em Saúde e Desenvolvimento) - Universidade Federal de Mato Grosso do Sul, Campo Grande, 2013.

FLORIO, Salvatore et al. Hydrocortisone has a protective effect on CyclosporinAinduced cardiotoxicity. Journal of cellular physiology, v. 195, n. 1, p. 21-26, 2003.

HAM, Sangwoo et al. Hydrocortisone-induced parkin prevents dopaminergic cell death via CREB pathway in Parkinson's disease model. Scientific reports, v. 7, n. 525, p. 1- 
13, 2017

LIAW, Kevin; ZHANG, Zhi; KANNAN, Sujatha. Neuronanotechnology for brain regeneration. Advanced Drug Delivery Reviews, v. 148, p. 3-18, 2019.

MAYES, Jennifer et al. $\beta$-amyloid fibrils in Alzheimer disease are not inert when bound to copper ions but can degrade hydrogen peroxide and generate reactive oxygen species. Journal of Biological Chemistry, v. 289, 17, p. 12052-12062, 2014.

MONTEIRO, Mariana Raquel; KANDRATAVICIUS, Ludmyla; LEITE, João Pereira. O papel das proteínas do citoesqueleto na fisiologia celular normal e em condições patológicas. J. epilepsy clin. neurophysiol, v. 17, n. 1, p. 17-23, 2011.

MORAES, Carlos Dailton Guedes de Oliveira et al. Genotoxic effects of photodynamic therapy in laryngeal cancer cells-An in vitro study. Experimental Biology and Medicine, v. 244, n. 3, p. 262-271, 2019.

MORALES, Inelia; FARÍAS, Gonzalo; MACCIONI, Ricardo B. La neuroinflamación como factor detonante del desarrollo de la enfermedad de Alzheimer. Revista chilena de neuro-psiquiatría, v. 48, n. 1, p. 49-57, 2010.

PRINCE, M.; JACKSON, J. Relatório sobre a Doença de Alzheimer no mundo. Londres (UK): Alzheimer's Disease International, 2010.

RABELO, Thallita Kelly. Caracterização redox-ativa do ácido úrico e seu efeito citotóxico em células SH-SY5Y. 2012. 50f. Dissertação (Mestrado em Ciências da Saúde) - Universidade Federal de Sergipe, Aracaju, 2012.

ROSSATO, Rafaella Carvalho et al. Hydrocortisone cytorestores oxidative stressinduced neuroblastoma. Alzheimer's \& Dementia: The Journal of the Alzheimer's Association, v. 15, n. 7, p. 642, 2019.

SALLES, Geisa Nogueira et al. A novel bioresorbable device as a controlled release system for protecting cells from oxidative stress from Alzheimer's Disease. Molecular neurobiology, v. 54, n. 9, p. 6827-6838, 2017.

SALLES, Geisa Nogueira, et al. Prolonged Drug-Releasing Fibers Attenuate Alzheimer's Disease-like Pathogenesis. ACS Applied materials \& interfaces, v. 10, n. 43, p. 36693-36702, 2018.

SALLES, Geisa Nogueira et al. Neuroprotective and restorative properties of the GLP$1 / G I P$ dual agonist DA-JC1 compared with a GLP-1 single agonist in Alzheimer's disease. Neuropharmacology, v. 162, 2020.

SOARES, António José de Almeida; ALVES, Maria da Graça Pereira. Cortisol como variável em psicologia da saúde. Psicologia, Saúde \& Doenças, v. 7, n. 2, p. 165$177,2006$. 